\title{
ОСНОВНЫЕ ПОДХОДЫ
}

И ПРИНЦИПЫ ПРОЕКТИРОВАНИЯ

МАГИСТЕРСКИХ ОБРАЗОВАТЕЛЬНЫХ ПРОГРАММ ПОДГОТОВКИ ПЕДАГОГОВ ДОПОЛНИТЕЛЬНОГО ИНЖЕНЕРНОГО ОБРАЗОВАНИЯ ${ }^{1}$

\author{
Л.В. Шкерина (Красноярск, Россия) \\ А.В. Багачук (Красноярск, Россия) \\ Ю.Ю. Бочарова (Красноярск, Россия)
}

\section{Аннотация}

Проблема и цель. Решение проблем ориентации обучающихся общеобразовательных школ на инженерные специальности всегда представляло интерес среди ученых и педагогов-практиков как в России, так и за рубежом. Для каждого технологического уклада решение этих проблем имеет свою специфику. В 2010 году зафиксировано начало шестого технологического уклада, который характеризуется такими отраслями, как: нано- и биотехнологии, наноэнергетика, молекулярная, клеточная и ядерная технологии, нанобиотехнологии, биомиметика, нанобионика, нанотроника и др. ${ }^{2}$

Для этих отраслей требуется новое поколение инженеров, обладающих системными междисциплинарными компетенциями, способных решать новые задачи новыми методами и средствами. Подготовка таких инженеров начинается с профессиональной ориентации школьников, которая должна отвечать современному технологическому укладу. Для решения новых задач профессиональной ориентации школьников на профессию инженера требуется специальная подготовка педагогов, владеющих современными знаниями и технологиями мотивации и обучения в контексте современного инженерного образования и профессиональной деятельности инженера. Такая подготовка может быть реализована посредством специальных магистерских программ. Цель статьи - в определении теоретических подходов и принципов проектирования образовательных программ подготовки педагога-магистра дополнительного инженерного образования школьников.
Методологию исследования составляют анализ программных и нормативных документов в области профессиональной ориентации обучающихся общеобразовательной школы, исследований отечественных и зарубежных ученых, посвященных реализации инженерной подготовки школьников, нормативных документов и действующих магистерских программ по направлению подготовки 44.04.01 Педагогическое образование; анализ и обобщение авторского опыта проектирования и реализации магистерских программ подготовки педагогов для средней общеобразовательной школы.

Результаты. Определены основные подходы и принципы проектирования магистерских образовательных программ подготовки педагогов дополнительного инженерного образования обучающихся общеобразовательной школы.

Заключение. Проведенный системный анализ педагогических исследований, программных и нормативно-правовых документов в сфере инженерного образования обучающихся общеобразовательной школы позволил определить подходы и сформулировать принципы проектирования результативных магистерских образовательных программ подготовки педагогов дополнительного инженерного образования обучающихся общеобразовательной школы.

Ключевые слова: профессиональная ориентация, инженерный профиль, дополнительное образование, технопарк, сетевая магистерская программа, бипрофессиональная подготовка педагога.

\footnotetext{
Проект «Педагогическая интернатура инженерно-технологической направленности: концепция и экспериментальная модель», исследование проведено при поддержке Красноярского краевого фонда науки.

2 Шесть технологических этапов. URL: https://general-skokov.livejournal.com/24586.html (дата обращения: 31.10.2019).
} 
$\Pi$ остановка проблемы. Для шестого технологического уклада характерны новые наукоемкие отрасли, требующие соответствующего инженерного корпуса, подготовка которого - главная задача современных образовательных учреждений высшего образования инженерных направлений. В этой связи объективирован запрос на абитуриента с высоким уровнем теоретической подготовки и устойчивой мотивацией к получению инженерного образования. Однако анализ результатов набора студентов на первый курс показывает, что для большинства образовательных учреждений высшего образования инженерных направлений подготовки невысок средний бал Единых государственных экзаменов ${ }^{3}$. Известны исследования, которые подтверждают невысокий уровень готовности студентов первого курса к освоению образовательных программ, в том числе инженерных профилей подготовки [Шашкина, 2018].

В Стратегии инновационного развития Российской Федерации на период до 2020 года подчеркивается: «Пока российские школьники значительно отстают от сверстников из других стран по умению анализировать, обобщать, прогнозировать, выдвигать гипотезы и т.д."; определяются современные требования к результатам подготовки выпускников: «Образование должно сформировать у учащихся новый уровень технологической компетенции и высокую креативность» ${ }^{4}$. Другими словами, подготовка инженеров начинается с профессиональной ориентации школьников, отвечающей современному технологическому укладу. Такая подготовка может реализовываться как посредством профильного обучения, так и в рамках дополнительного образования. Предоставление обучающимся условий свободного личностного

\footnotetext{
3 Вузы Красноярска 2019: университеты, институты... URL: https://krasnoyarsk.postupi.online/vuzi/ (дата обращения: 31.10.2019).

4 Стратегия инновационного развития Российской Федерации на период до 2020 года, утвержденная распоряжением Правительства Российской Федерации от 8 декабря 2011 г. № 2227-p. С. 181. URL: https://www.garant. ru/products/ipo/prime/doc/70006124/ (дата обращения: 31.10.2019).
}

выбора деятельности, определяющей индивидуальное развитие человека, является одной из специфических характеристик дополнительного образования, дающей ему конкурентные преимущества. Концепция развития дополнительного образования детей направлена на воплощение в жизнь миссии дополнительного образования как социокультурной практики развития мотивации подрастающих поколений к познанию, творчеству, труду, превращение феномена дополнительного образования в подлинный системный интегратор открытого вариативного образования, обеспечивающего конкурентоспособность личности ${ }^{5}$. В 2015 году дан старт Стратегической инициативе «Новая модель системы дополнительного образования детей». Необходимость изменений продиктована вызовами инновационной экономики и усилением глобального научно-технического развития. В рамках инициативы решается задача воспитания лидеров будущего, подготовка которых начинается с формирования навыков XXI века, таких как технологические компетенции, умение работать в команде, эффективная коммуникация. Для этого используются новые формы образования, учитывающие мотивацию детей и подростков к обучению 6 .

Среди них особую популярность имеют так называемые детские технопарки.

Для решения новых задач профессиональной ориентации школьников на профессию инженера требуется специальная подготовка педагогов, владеющих современными знаниями и технологиями мотивации и обучения в контексте современного инженерного образования и профессиональной деятельности инженера. Поиск путей реализации такой подготовки педагога составляет актуальную научную педагогическую проблему.

\footnotetext{
5 Концепция развития дополнительного образования детей. Утверждена распоряжением Правительства Российской Федерации от 4 сентября 2014 г. № 1726-р: URL: https://volok-ddtudod.edumsko.ru/documents/other_ documents/doc/21237 (дата обращения: 31.10.2019).

6 Стратегическая инициатива «Новая модель системы дополнительного образования», одобренная Президентом Российской Федерации 27 мая 2015 r. URL: https://asi.ru/ future_skills/ (дата обращения: 01.11.2019).
} 
Цель статьи - в определении теоретических подходов и принципов проектирования образовательных программ подготовки педагогамагистра дополнительного инженерного образования школьников.

Методологию исследования составили: компетентностный подход к высшему образованию как основа требований к составу компетенций будущего педагога в сфере инженерного образования школьников (И.А. Зимняя, С.И. Осипова и др.); положения системно-деятельностного подхода к основному и дополнительному образованию обучающихся общеобразовательной школы (С.В. Каплевская, В.С. Лазарев, С.В. Скорых и др.); основные положения педагогического проектирования как теоретическая основа проектирования образовательных программ (В.К. Власова, Н.С. Ковалева, Ю.В. Макаренко и др.); исследования отечественных и зарубежных ученых в области инженерно-технологической подготовки школьников (М.Н. Гутенев, Д.Д. Махотин, Д.Р. Мерзлякова, А.А. Мирошниченко, A.H. Соловьев, А.Н. Чайка, D. Bell, A. Rasinen, C. Rogers) и подготовки педагогов к реализации инженерного образования школьников (А.А. Калекин, В.И. Сопин, Г.Н. Варковецкая, Т.О. Мишина, С.М. Конюшенко и др.); нормативные требования федеральных государственных образовательных стандартов высшего образования по направлению подготовки Педагогическое образование, профессионального стандарта педагога; программные и нормативные документы в области профессиональной ориентации обучающихся общеобразовательной школы; анализ действующих примерных и реализуемых магистерских программ по направлению подготовки Педагогическое образование.

Обзор научной литературы. Проблемы дополнительного образования обучающихся общеобразовательной школы всегда были в центре внимания исследователей. На разных этапах развития отечественного образования для их решения использовались соответствующие подходы, формы и методы обучения. На сегодняшний день актуализируются задачи реализации профильного инженерного образования в общеобразова- тельной школе. Д.А. Махотин исследует вопросы определения содержания обучения в инженерных классах на основе интегративного подхода и его реализации посредством элективных курсов интегративной направленности; проблематики исследовательских работ и проектов; использования специализированного лабораторного оборудования [Махотин, 2016, с. 157-158].

Особенности методики обучения и воспитания в профильных инженерно-технологических классах в области Национальной технологической инициативы (НТИ) ${ }^{7}$ рассматривались в работах Д.Р. Мерзляковой и А.А. Мирошниченко, которые предлагают обучать школьников новым технологиям в рамках НТИ посредством выстраивания индивидуальных траекторий с углубленным изучением отдельных предметов (физика, математика, информатика и т.д.). Также необходимо участие школьников в кружках по данному направлению и профильных олимпиадах» [Мерзлякова, Мирошниченко, 2018, с. 2015].

В работах Н.В. Гафуровой, С.С. Граськина, Е.Е. Граськиной, В.И. Лях, С.И. Осиповой, А.Н. Соловьева, И.П. Черновой и др. предлагаются результативные подходы и технологии реализации профильной инженерной подготовки обучающихся в условиях интеграции образовательных ресурсов и социального партнерства университетов, производственных компаний и общеобразовательных школ [Граськин, Граськина, 2019; Соловьев, 2017; Чернова и др., 2012].

Особое внимание ученых в настоящее время привлекает изучение новых форм инженерного образования обучающихся общеобразовательной школы - детских технопарков. Изучается потенциал Кванториумов в системе дополнительного инженерного образования обучающихся и условия его реализации [Аксенова, 2018; Назарова, Барабаш, 2019; Чайка, 2017; и др.].

Вопросы организации и реализации инженерной допрофессиональной подготовки детей активно исследуются зарубежными учеными [Bell, 2016; Kaufmann, Koc, 2018; Rasinen, 2003; Rogers, 2016].

\footnotetext{
7 Национальная технологическая инициатива. URL: http:// www.nti2035.ru/nti/ (дата обращения: 08.11.2019).
} 
Решение задач инженерной подготовки обучающихся общеобразовательной школы на современном этапе невозможно без соответствующей подготовки педагогов. Ученые ведут поиск реализации такой подготовки в системе педагогического образования, профессиональной переподготовки и повышения квалификации.

А.А. Калекин изучает методологию инженерной педагогики школы как учение о наиболее общих закономерностях, принципах, методах жизненного и профессионального получения будущим бакалавром технологии в вузе инженерных знаний для их последующей реализации в школе при подготовке учащихся к обоснованному профессиональному самоопределению в сфере современного материального производства путем выбора профиля обучения в старших классах [Калекин, 2014].

Т.О. Мишина и С.М. Конюшенко обосновывают возможность подготовки педагогов для работы в технопарке «Кванториум» посредством курсов повышения квалификации, где внимание акцентируется на освоении "hard-компетенциий» (умение работать на цифровом оборудовании, в частности на лазерных, фрезерных и гравировочных станках, работать на 3-D принтерах, SMART-досках, компьютерах, с очками виртуальной и дополненной реальности, плоттером и фотоаппаратом) [Мишина, Конюшенко, 2017].

В.И. Сопин и Г.Н. Варковецкая обосновывают целесообразность в современных условиях предоставлять возможность освоения педагогических компетенций лицам, не имеющим базового педагогического образования. Для подготовки, переподготовки и повышения квалификации педагогических кадров необходимо обновить образовательные программы бакалавриата, магистратуры и дополнительного профессионального образования по педагогическим специальностям [Сопин, Варковецкая, 2013].

Проведенный анализ научных публикаций по изучаемой проблеме обнаружил отсутствие в них концептуальных подходов к разработке образовательных программ подготовки педагогов для дополнительного инженерного образования.
Результаты исследования. Сформулированы и обоснованы подходы к проектированию магистерских образовательных программ подготовки педагогов дополнительного инженерного образования обучающихся общеобразовательной школы.

Компетентностный подход как основа моделирования требований к результатам освоения, согласующихся с трудовыми функциями и действиями в профессиональном стандарте педагога.

Социокультурный подход как основа проектирования содержательного компонента образовательной программы, ориентированного на особенности территории и решение социальноэкономических проблем региона.

Системно-деятельностный подход положен в основу проектирования технологического компонента, выбора методов, способов и средств обучения, обеспечивающих создание основных условий реализации деятельности обучающихся, адекватной формируемым компетенциям.

Сетевой подход открывает возможность проектирования открытой образовательной среды, интеграции ресурсов университетов, «ресурсных центров» инженерного дополнительного образования, государственных и негосударственных предприятий.

Для реализации названных подходов при проектировании магистерских образовательных программ подготовки педагогов дополнительного инженерного образования обучающихся общеобразовательной школы определен комплекс принципов.

Принцип бипрофессиональности отражает специфику требований к результатам подготовки выпускников - владение компетенциями педагога в формате требований федерального государственного образовательного стандарта, направление подготовки 44.04.01 Педагогическое образование, и дополнительными компетенциями в области основ инженерного образования и методики реализации дополнительных образовательных программ инженерной подготовки обучающихся. 
Принцип модульности позволяет структурировать учебный материал теоретической подготовки и практики для создания профессионального контекста, ориентированного на обеспечение видов деятельности, результатом которых являются требуемые компетенции.

Принцип вариативности позволяет проектировать альтернативные учебные модули подготовки магистров как педагогической, так и инженерной направленности. Это позволит проектировать образовательные программы, ориентированные на обучение лиц, имеющих как педагогическое, так и инженерное образование (лиц, не имеющих базового педагогического образования).

Принцип интегративности как требование объединения образовательных ресурсов университетов, технопарков, производителей и других участников образовательных отношений при проектировании и реализации магистерских программ подготовки педагогов для дополнительного инженерного образования обучающихся общеобразовательных школ.

Заключение. Проведенный системный анализ педагогических исследований, программных и нормативно-правовых документов в сфере инженерного образования обучающихся общеобразовательной школы позволил определить подходы (компетентностный, социокультурный, системно-деятельностный, сетевой) и сформулировать принципы (бипрофессиональности, модульности, вариативности, интегративности) проектирования результативных магистерских образовательных программ подготовки педагогов дополнительного инженерного образования обучающихся общеобразовательной школы.

\section{Библиографический список}

1. Аксенова М.А. Кванториум - инновационная форма дополнительного образования детей и молодежи // Воспитание детей - инвестиции в будущее!: сб. ст. III Всерос. форума / отв. ред. А.А. Сергеенко. 2018. C. 35-38. URL: https://elibrary.ru/download/ elibrary_37083539_80910928.pdf (дата обращения: 20.10.2019).
2. Власова В.К. Интеграционная основа проектирования содержания современного педагогического образования // Казанский педагогический журнал. 2012. № 3 (93). C. 17-21. URL: https://elibrary.ru/download/ elibrary_18987380_84925057.pdf (дата обращения: 20.10.2019).

3. Граськин С.С., Граськина Е.Е. Концептуальная модель системной матрицы предпрофильной инженерной подготовки школьников // Моделирование и конструирование в образовательной среде: сб. матер. IV Всерос. (с междунар. участием) науч.-практ., методолог. конф. для науч.-пед. сообщества / под ред. И.А. Артемьева, В.О. Белевцовой, Н.Д. Дудиной, М.Н. Бученковой. 2019. С. 69-74. URL: https://elibrary. ru/download/elibrary_37615990_12441384.pdf (дата обращения: 20.10.2019).

4. Гутенев М.Н. Развитие системы инженернотехнологического образования современных школьников // Педагогика: матер. 57-й Междунар. науч. студ. конф. Новосибирск, 2019. C. 23-25. URL: https://elibrary.ru/ download/elibrary_38320728_40088479.pdf (дата обращения: 20.10.2019).

5. Зимняя И.А. Компететностный подход. Какого его место в системе современных подходов к проблемам образования? (Теоретикометодологический аспект) // Высшее образование сегодня. 2006. № 8. C. 20-26. URL: https://elibrary.ru/item.asp?id=21594618 (дата обращения: 20.10.2019).

6. Калекин А.А. Инженерная педагогика школы // Ученые записки Орловского государственного университета. Сер.: Гуманитарные и социальные науки. 2014. № 1 (57). C. 344-350. URL: https://elibrary.ru/download/ elibrary_22298382_25543954.pdf (дата обращения: 20.10.2019).

7. Каплевская С.В. Реализация системнодеятельностного подхода в практике дополнительного образования // Актуальные проблемы современного образования. 2016. № 1 (20). C. 176-184. URL: https://elibrary.ru/ download/elibrary_26709538_88933694.pdf (дата обращения: 20.10.2019). 
8. Ковалева Н.С., Авдеева И.Н. Научные основы проектирования основных образовательных программ по педагогическому образованию // Концептуальные подходы к проектированию основных образовательных программ по педагогическому образованию: кол. монография. Севастополь, 2019. C. 8-21. URL: https://elibrary.ru/download/ elibrary_37352350_79286324.pdf (дата обращения: 20.10.2019).

9. Лазарев В.С., Коноплина Н.В. Деятельностный подход к формированию содержания педагогического образования // Педагогика. 2000. № 3. С. 27-34. URL: https://elibrary. ru/item.asp?id=25765259 (дата обращения: 20.10.2019).

10. Макаренко Ю.В. Педагогическое проектирование: анализ теоретико-методологических основ // Проблемы современного педагогического образования. 2017. № 57-2. C. 154-161. URL: https://elibrary.ru/download/ elibrary_30710762_64311959.pdf (дата обращения: 20.10.2019).

11. Махотин Д.А. Инженерная подготовка в технологическом образовании школьников // Казанский педагогический журнал. 2016. № 2, т. 2. С. 301-305. URL: https://elibrary.ru/ download/elibrary_25899585_10675332.pdf (дата обращения: 20.10.2019).

12. Мерзлякова Д.Р., Мирошниченко А.А. Разработка методики обучения школьников в профильных инженерно-технологических классах // Современные наукоемкие технологии. 2018. № 10. С. 211-215. URL: https://elibrary. ru/download/elibrary_36403546_11627023. pdf (дата обращения: 20.10.2019).

13. Мишина Т.О., Конюшенко С.М. Формирование компетенций педагога дополнительного образования в детском технопарке «Кванториум» // Научные исследования: теория, методика и практика: сб. матер. III Междунар. науч.-практ. конф.: в 2 т. / редкол.: О.Н. Широков и др. 2017. С. 137-139. URL: https://elibrary.ru/download/elibrary_ 32334700_36987588.pdf (дата обращения: 20.10.2019).
14. Назарова Я.А., Барабаш М.В. Особенности функционирования и архитектурного формирования детских технопарков в России и за рубежом // Вестник Белгородского государственного технологического университета им. В.Г. Шухова. 2019. № 8. С. 40-48. URL: https://elibrary.ru/item.asp?id=39559309 (дата обращения: 20.10.2019).

15. Осипова С.И. Компетентностный подход в реализации инженерного образования // Педагогика. 2016. № 6. С. 53-59. URL: https:// elibrary.ru/item.asp?id=26535252 (дата обращения: 20.10.2019).

16. Скорых С.В. Системно-деятельностный подход в образовании // Новая наука: современное состояние и пути развития. 2016. № 6-2. C. 93-95. URL: https://elibrary.ru/ download/elibrary_28144501_30851724. pdf (дата обращения: 20.10.2019).

17. Соловьев А.Н. Подготовка школьников к инженерному образованию в Москве и США // Автомобиль. Дорога. Инфраструктура: электронный научный журнал. 2017. № 1 (11). C. 124-140. URL: https://elibrary.ru/download/ elibrary_29069419_80715920.pdf (дата обращения: 20.10.2019).

18. Сопин В.И. Варковецкая Г.Н. Проблемы подготовки преподавателей без базового педагогического образования // Человек и образование. 2013. № 4 (37). С. 43-49. URL: https:// elibrary.ru/download/elibrary_21057096_ 34102303.pdf (дата обращения: 20.10.2019).

19. Чайка А.Н. Кванториум - новый российский формат дополнительного образования детей в сфере инженерных наук // Наука и образование: Новое время. 2017. № 3 (4). C. 122-124. URL: https://elibrary.ru/download/ elibrary_29417818_10472085.pdf (дата обращения: 20.10.2019).

20. Чернова И.П., Осипова С.И., Гафурова Н.В., Лях В.И. Инновационная практика профильного образования с ориентацией на потребности корпораций региона//Высшее образованиесегодня. 2012. № 8. C. 10-16. URL: https://elibrary. ru/download/elibrary_19068924_15400826.pdf (дата обращения: 20.10.2019). 
21. Шашкина М.Б. Проблемы качества математической подготовки обучающихся по результатам пофильного ЕГЭ 2018 // Актуальные проблемы качества математической подготовки школьников и студентов: методологический, теоретический и технологический аспекты: матер. VI Всерос. с междунар. участием науч.метод. конф. Красноярск, 2018. С. 13-19. URL: https://elibrary.ru/item.asp?id=37040961 (дата обращения: 20.10.2019).

22. Bell D. The reality of STEM education, design and technology teachers» perceptions: a phenomenographic study // International Journal of Technology and Design Education. February. 2016. Vol. 26, is. 1. P. 61-79. URL: https://link. springer.com/article/10.1007/s10798-0159300-9 (дата обращения: 05.11.2019).
23. Kaufmann M., Koc H. Forschendes Lernen in der curricularen Profilbildung // Forschendes Lernen in den Geisteswissenschaften. 2018. P. 79-102. URL: https://link.springer.com/ chapter/10.1007/978-3-658-21738-9_5 (дата обращения: 05.11.2019).

24. Rasinen A. An analysis of the technology education curriculum of six countries // Journal of Technology Education. 2003. Vol. 15. No. 1. P. 31-47. URL: https://scholar.lib.vt.edu/ ejournals/JTE/v15n1/pdf/rasinen.pdf (дата обращения: 20.10.2019).

25. Rogers C. Hit the bricks // Prism. American Society for Engineering Education. February 2016. Vol. 25, No 6. P. 25. URL: https://www. questia.com/magazine/1P3-3954049351/hitthe-bricks (дата обращения: 20.10.2019). 


\section{BASIC APPROACHES AND PRINCIPLES OF DESIGNING MASTER'S EDUCATIONAL PROGRAMS FOR TRAINING TEACHERS IN ADDITIONAL ENGINEERING EDUCATION}

\author{
L.V. Shkerina (Krasnoyarsk, Russia)
}

A.V. Bagachuk (Krasnoyarsk, Russia)

Yu.Yu. Bocharova (Krasnoyarsk, Russia)

Abstract

Statement of the problem. The solution of problems related with orientation of secondary school students towards engineering specialties has always been of interest among scientists and teachers-practitioners both in Russia and abroad. For each technological paradigm, the solution of these problems has its own specificity. In 2010, the beginning of the sixth technological paradigm was recorded. It is characterized by such industries as nano- and biotechnology, nanoenergy, molecular, cellular and nuclear technologies, nanobiotechnologies, biomimetics, nanobionics, nanotronics, etc.

These industries require a new generation of engineers with systemic interdisciplinary competencies, capable of solving new challenges with new methods and means. Training of such engineers begins with the vocational orientation of schoolchildren, which should be in line with the modern technological paradigm. In order to solve the new problems of professional orientation of schoolchildren towards the profession of an engineer, special training of teachers with modern knowledge and technologies of motivation and training in the context of modern engineering education and professional activity of the engineer is required. Such training can be carried out through special master's programmes.

The purpose of the article is to define theoretical approaches and design principles of master degree edu-

\section{References}

1. Aksenova M.A. Kwantorium is an innovative form of additional education of children and young people. In: Collection of articles of the III All-Russian Forum "Raising children is an investment in the future!" (edited by A.A. Sergiyenko). 2018. P. 35-38. URL: https://elibrary.ru/ download/elibrary_37083539_80910928.pdf (access date: 20.10.2019).

2. Vlasova V.K. Integration basis for designing modern pedagogical education content // Kazanskiy pedagogicheskiy zhurnal (Kazan Pedagogical Journal). 2012. No. 3 (93). cational programs for teachers training in additional engineering education for schoolchildren.

The methodology of the study is the analysis of program and regulatory documents in the field of vocational orientation of secondary school students, studies of Russian and international scientists devoted to the implementation of engineering training for schoolchildren, regulatory documents and existing master's programs in 44.04.01 Pedagogical education; analysis and synthesis of the authors' experience in designing and implementing master's programs for training secondary school teachers.

Research results. The main approaches and principles have been defined of designing master»s educational programs for training teachers in additional engineering education for secondary school students.

Conclusion. The system analysis of pedagogical studies, program and regulatory documents in the field of engineering education for secondary school students made it possible to define approaches and formulate principles for designing effective master»s educational programs for training teachers in additional engineering education for secondary school students.

Keywords: professional orientation, engineering profile, additional education, technopark, network master's program, bi-professional training of a teacher.

P. 17-21. URL:https://elibrary.ru/download/ elibrary_18987380_84925057.pdf (access date: 20.10.2019).

3. Graskin S.S., Graskina E.E. Conceptual model of the system matrix for pre-profile engineering training of schoolchildren. In: Collection of materials of the IV All-Russian (with international participation) scientific, practical, and methodological conference for the scientific and pedagogical community "Modeling and design in the educational environment" (ed. by I.A. Artemiev, V.O. Belevtsova, N.D. Dudina, M.N. Buchenkova). 2019. P. 69-74. URL: https://elibrary.ru/ 
download/elibrary_37615990_12441384.pdf (access date: 20.10.2019).

4. Gutenev M.N. Development of the system for engineering and technological education of modern schoolchildren. In: Proceedings of the 57th International Scientific Student Conference "Pedagogy". Novosibirsk, 2019. P. 23-25. URL: https://elibrary.ru/download/ elibrary_38320728_40088479.pdf (access date: 20.10.2019).

5. Zimnyaya I.A. Competence approach. What is its place in the system of modern approaches to education? (Theoretical and methodological aspect) // Vysshee obrazovanie segodnya (Higher education today). 2006. No. 8. P. 20-26. URL: https://elibrary.ru/item.asp?id=21594618 (access date: 20.10.2019).

6. Kalekin A.A. Engineering school pedagogy // Uchenye zapiski Orlovskogo gosudarstvennogo universiteta. Seriya: Gumanitarnye i sotsialnye nauki (Scientists Notes of the Oryol State University. Series: Humanities and Social Sciences). 2014.No.1(57).P.344-350.URL: https://elibrary. ru/download/elibrary_22298382_25543954. pdf (access date: 20.10.2019).

7. Kaplevskaya S.V. Implementation of the systemactivity approach in the practice of additional education // Aktualnye problemy sovremennogo obrazovaniya (Topical problems of modern education). 2016. No. 1 (20). P. 176-184. URL: https://elibrary.ru/download/elibrary_ 26709538_88933694.pdf (access date: 20.10.2019).

8. Kovaleva N.S., Avdeyeva I.N. Scientific basis for designing the main educational programs on pedagogical education. In: Conceptual approaches to designing basic educational programs on pedagogical education: a collective monograph. Sevastopol, 2019. P. 8-21. URL:https://elibrary. ru/download/elibrary_37352350_79286324. pdf (access date: 20.10.2019).

9. Lazarev V.S., Konoplina N.V. Activity approach to the formation of the content of pedagogical education // Pedagogika (Pedagogics). 2000. No. 3. P. 27-34. URL: https://elibrary.ru/item. asp?id=25765259 (access date: 20.10.2019).
10. Makarenko Yu.V. Pedagogical design: analysis of theoretical and methodological foundations // Problemy sovremennogo pedagogicheskogo obrazovaniya (Problems of Modern Pedagogical Education). 2017. No. 57-2. P. 154161. URL: https://elibrary.ru/download/elibrary_30710762_64311959.pdf (access date: 20.10.2019).

11. Makhotin D.A. Engineering training in technological education of schoolchildren // Kazanskiy pedagogicheskiy zhurnal (Kazan Pedagogical Journal). 2016. No. 2, vol. 2. P. 301-305. URL: https://elibrary.ru/download/elibrary_ 25899585_10675332.pdf (access date: 20.10.2019).

12. Merzlyakova D.R., Miroshnichenko A.A. Development of a methodology for teaching schoolchildren in specialized engineering and technological classes // Sovremennye naukoemkie tekhnologii (Modern knowledge-intensive technologies). 2018. No. 10. P. 211-215. URL: https://elibrary.ru/download/elibrary_ 36403546_11627023.pdf (access date: 20.10.2019).

13. Mishina T.O., Konyushenko S.M. Development of competences among teachers of additional education in children's technopark "Kwantorium" . In: Proceedings of the III International Scientific and Practical Conference "Scientific research: theory, methodology and practice" (in two volumes; edited by O.N. Shirokov et al.). 2017. P. 137-139. URL: https://elibrary.ru/ download/elibrary_32334700_36987588.pdf (access date: 20.10.2019).

14. Nazarova Y.A., Barabash M.V. Peculiarities of functioning and architectural formation of children's technoparks in Russia and abroad // Vestnik Belgorodskogo gosudarstvennogo tekhnologicheskogo universiteta im. V.G. Shukhova (Journal of the V.G. Shukhov State University of Technology). 2019. No. 8. P. 40-48. URL: https://elibrary.ru/item.asp?id=39559309 (access date: 20.10.2019).

15. Osipova S.I. Competent approach in the implementation of engineering education // Pedagogika (Pedagogy). 2016. No. 6. P. 53-59. URL: 
https://elibrary.ru/item.asp?id=26535252 (access date: 20.10.2019).

16. Soloviev A.N. Preparation of schoolchildren for engineering education in Moscow and the USA // Avtomobil. Doroga. Infrastruktura. Elektronnyy nauchnyy zhurnal (Car. Road. Infrastructure. Electronic scientific journal). 2017. No. 1 (11). P. 124-140. URL: https://elibrary.ru/ download/elibrary_29069419_80715920.pdf (access date: 20.10.2019).

17. Skorykh S.V. System-activity approach in education // Novaya nauka: Sovremennoe sostoyanie i puti razvitiya (New science: Modern state and ways of development). 2016. No. 6-2. P. 93-95. URL: https://elibrary.ru/download/ elibrary_28144501_30851724. Pdf (access date:: 20.10.2019).

18. Sopin V.I., Varkovetskaya G.N. Problems of teacher training without basic pedagogical education //Cheloveki obrazovanie (Person and education). 2013. No. 4 (37). P. 43-49. URL: https://elibrary. ru/download/elibrary_21057096_34102303.pdf (access date: 20.10.2019).

19. Chayka A.N. Kwantorium - a new Russian format of additional education for children in the field of engineering sciences // Nauchno-metodicheskiy zhurnal "Nauka i obrazovanie: novoe vremya" (Scientific and methodological journal "Science and education: a new time"). 2017. No. 3 (4). P. 122-124. URL: https://elibrary.ru/ download/elibrary_29417818_10472085.pdf (access date: 20.10.2019).

20. Chernova I.P., Osipova S.I., Gafurova N.V., Lyakh V.I. Innovative practice of specialized education oriented to the needs of corporations of the region // Vysshee obrazovanie segodnya (Higher education today). 2012. No. 8.
P. 10-16. URL: https://elibrary.ru/download/ elibrary_19068924_15400826.pdf

21. Shashkina M.B. Problems of quality in mathematical training of students according to the results of the Single State Exam 2018. In: Proceedings of the VI All-Russian (with international participation) scientific and methodological conference "Current problems in quality of mathematical training of schoolchildren and students: methodological, theoretical and technological aspects. Krasnoyarsk, 2018. P. 13-19. URL: https://elibrary.ru/item. asp?id=37040961 (access date: 20.10.2019).

22. Bell D. The reality of STEM education, design and technology teachers' perceptions: a phenomenographic study // International Journal of Technology and Design Education. February. 2016. Vol. 26, is. 1. P. 61-79. URL: https://link. springer.com/article/10.1007/s10798-0159300-9 (access date: 05.11.2019).

23. Kaufmann M., Koc H. Forschendes Lernen in der curricularen Profilbildung // Forschendes Lernen in den Geisteswissenschaften. 2018. P. 79-102. URL: https://link.springer.com/ chapter/10.1007/978-3-658-21738-9_5 (access date: 05.11.2019).

24. Rasinen A. An analysis of the technology education curriculum of six countries// Journal of Technology Education. 2003. Vol. 15, No. 1. P. 31-47. URL: https://scholar.lib.vt.edu/ejournals/JTE/v15n1/pdf/rasinen.pdf (access date: 20.10.2019).

25. Rogers C. Hit the bricks // Prism. American Society for Engineering Education. February 2016. Vol. 25, No. 6. P. 25. URL: https://www. questia.com/magazine/1P3-3954049351/hitthe-bricks (access date: 20.10.2019). 